\title{
Correction to: Cognitive behavioral therapy for primary care depression and anxiety: a secondary meta-analytic review using robust variance estimation in meta-regression
}

\author{
Anao Zhang ${ }^{1} \mathbb{D} \cdot$ Lindsay A. Bornheimer ${ }^{1}$. \\ Addie Weaver ${ }^{1}$ Cynthia Franklin ${ }^{2}$.

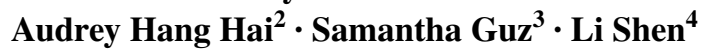

Published online: 9 January 2020

(C) Springer Science+Business Media, LLC, part of Springer Nature 2020

Correction to: J Behav Med (2019) 42:1117-1141

https://doi.org/10.1007/s10865-019-00046-Z

The original version of this article unfortunately contained a typo in the second author surname. The author surname was incorrectly listed as Borhneimer. The correct name should be Bornheimer.

The original article can be found online at https://doi. org/10.1007/s10865-019-00046-z.

Anao Zhang

zhangan@umich.edu

1 School of Social Work, University of Michigan, 1080

S. University Ave., School of Social Work Building,

Ann Arbor, MI 48109, USA

2 Steve Hicks School of Social Work, The University of Texas at Austin, Austin, TX, USA

3 School of Social Service Administration, The University of Chicago, Chicago, IL, USA

4 Department of Sociology and Social Work, Shanghai Normal University, Shanghai, China 